\title{
El ambiente comunitario y fraterno como eje en el trabajo evangelizador de la pastoral juvenil \\ The atmosphere as an evangelist of community and fraternity
}

María Verónica Di Caudo

Universidad Politécnica Salesiana mdicaudo@ups.edu.ec

Recibido: 29 de enero de 2013 / Aceptado: 28 de junio de 2013

"Me gustó porque cuando llegué me saludaron cómo si me hubieran conocido. Me aceptan y me tratan bien. Nos escuchamos todos. En este grupo me gusta estar...está chévere”.

(Gustavo, 19 años)

\section{Resumen}

Este artículo destaca la importancia clave del ambiente como evangelizador en sí mismo. Dentro del trabajo con y entre jóvenes en parroquias, grupos y comunidades, movimientos, instituciones educativas un clima de testimonio, fraternidad, fe y buen trato que tome a Jesús como modelo, lleva a dignificar a la persona, en miras a procesos integrales de conversión. Por tanto, la opción de construir un ambiente evangelizador -fundamentado en dimensiones antropológicas comunitarias y kerygmáticas- no puede quedar ajeno a cuestiones pedagógicas y formativas en el trabajo con la Pastoral Juvenil.

\section{Palabras claves}

Pastoral juvenil, fraternidad, testimonio, ambiente evangelizador.

\begin{abstract}
This article highlights the key importance of the evangelical environment itself. Through work with and between youth in parishes, groups and communities, movements, and educational institutions; an atmosphere of testimony, fraternity, faith and good relationships that look at Jesus' example, dignifies a person towards integral processes of spiritual change. Consequently, the option of building an evangelical environment - supported by community and kerygmatic anthropological dimensions - in the pastoral youth service work, cannot stay unconnected from pedagogical and formative issues.
\end{abstract}

\section{Keywords}

Pastoral youth service, fraternity, testimony, evangelical environment.

Forma sugerida de citar:

Di Caudo, M. (2013). El ambiente comunitario y fraterno como eje en el trabajo evangelizador de la pastoral juvenil. Alteridad, 8(1), pp. 38-50. Quito: Editorial Abya-Yala. 


\section{I - Introducción}

La Pastoral Juvenil es un espacio para generar la fuerza de la vida y la capacidad de opciones que los jóvenes tienen, re-destapar búsquedas profundas y sed de valores. Centraremos nuestra reflexión en el ambiente de la pastoral; ambiente que resulta ser trascendental porque acompaña la formación, fortalece la apropiación de contenidos y evangeliza integralmente a la persona. Podemos pensar en un contexto que se hace texto y es entonces, cuando entendemos que no sólo el "contenido pedagógico-formativo" (bíblico, doctrinal, catequístico) es el que alimenta, sino que será mucho más "nutritivo" para nuestra vida espiritual cuando se lo asimile en medio de una experiencia de buen trato, fraternidad, encuentro, alegría y testimonio.

Los desafíos son muy grandes y aquí me permito citar a Benedicto XVI, en la Eucaristía que abrió el año de la Fe del 11 de octubre del 2012:

En estos decenios ha aumentado la «desertificación» espiritual. Si ya en tiempos del Concilio se podía saber, por algunas trágicas páginas de la historia, lo que podía significar una vida, un mundo sin Dios, ahora lamentablemente lo vemos cada día a nuestro alrededor. Se ha difundido el vacío. Pero precisamente a partir de la experiencia de este desierto, de este vacío, es cómo podemos descubrir nuevamente la alegría de creer, su importancia vital para nosotros, hombres y mujeres. En el desierto se vuelve a descubrir el valor de lo que es esencial para vivir; así, en el mundo contemporáneo, son muchos los signos de la sed de Dios, del sentido último de la vida, a menudo manifestados de forma implícita o negativa. $\mathrm{Y}$ en el desierto se necesitan sobre todo personas de fe que, con su propia vida, indiquen el camino hacia la Tierra prometida y de esta forma mantengan viva la esperanza. La fe vivida abre el corazón a la Gracia de Dios que libera del pesimismo. Hoy más que nunca evangelizar quiere decir dar testimonio de una vida nueva, trasformada por Dios, y así indicar el camino.
El punto de partida de la Pastoral Juvenil es el propio joven, asumido en su realidad personal, cultural y social. A partir del impulso dado por los obispos en Medellín y Puebla (1968, 1979), se han realizado múltiples encuentros en diferentes países de nuestro continente ${ }^{1}$ con una valiosa experiencia de intercambio y una rica reflexión teológico-pastoral que han permitido elaborar y presentar una "propuesta global, la Civilización del Amor; una metodología para el trabajo grupal y una pedagogía para acompañar los procesos de formación humana y cristiana de los jóvenes" (SEJ-CELAM, 1995: 80). El manual de reflexión para los grupos juveniles del continente reconoce que el desafío principal sigue siendo "acompañar los procesos de formación integral que lleven a los jóvenes a ser protagonistas en la sociedad hoy, a través de un proyecto de vida fundado en el seguimiento de Jesús" (SEJ-CELAM: 2006).

Jorge Mario Bergoglio (hoy Papa Francisco) siendo Cardenal en su informe en la V Conferencia General del Episcopado Latinoamericano en Aparecida, también manifestaba los cambios que la Pastoral Juvenil demanda, con estas palabras:

La pastoral juvenil, tal como estábamos acostumbrados a llevarla adelante ha sufrido el embate de los cambios sociales, y los jóvenes, en las estructuras habituales, muchas veces no encuentran respuestas a sus inquietudes, necesidades, problemática y heridas. Si bien es difícil abordar a los jóvenes, se está creciendo en dos aspectos: la conciencia de que es toda la comunidad la que los evangeliza y la urgencia de que ellos tengan un protagonismo mayor que les permita valorar y descubrir el sentido de sus vidas.

1 Citemos algunos de ellos: en Fusagasugá, Colombia (1983), Zipaquirá, Colombia (1984), Bogotá, Colombia (1985, 1986 y 1987), Caracas, Venezuela (1988), Quito, Ecuador (1989), San José, Costa Rica (1990), Zipaquirá, Colombia (1993), Mogi das Cruzes, Brasil (1994), Aguadilla, Puerto Rico (1996), México D.F (1997), Buenos Aires, Argentina, (2001), Quito, Ecuador (2003) y Panamá (2007). 


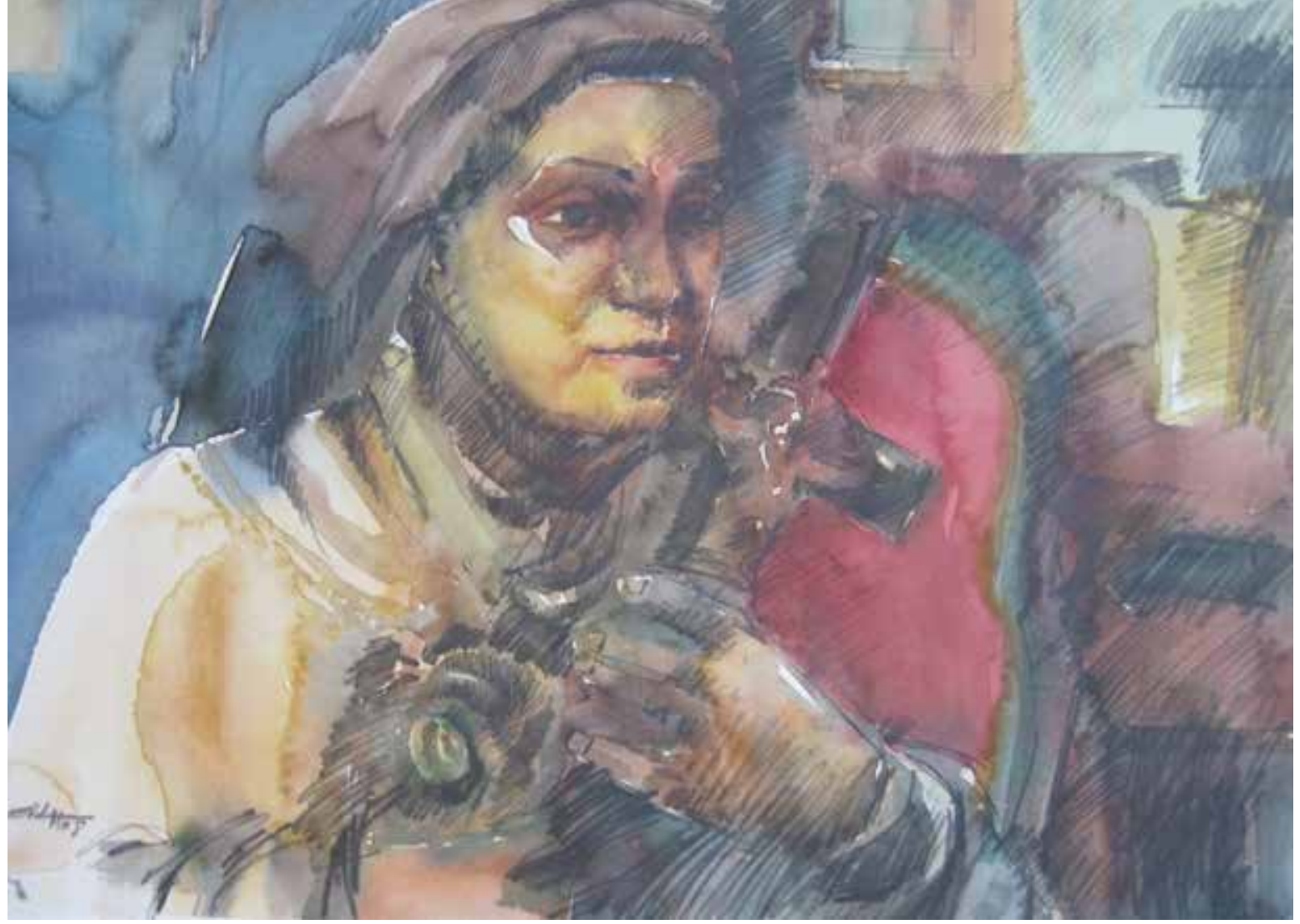

Demostración de fe, acuarela

La Pastoral Juvenil no inventa a los jóvenes, en el nombre de Jesús, los encuentra como son y donde están. La escena de "desertificación espiritual" (usando las palabras de Benedicto) o del "embate" (según el Papa Francisco) en el siglo XXI, es el contexto real y concreto en el cual estamos llamados a trabajar no sólo para los jóvenes sino con los jóvenes y entre los jóvenes.

En un mundo que trata mal, en medio de violencias múltiples y variadas, de relativismos y soledades, de contextos sociales masificantes y despersonalizantes, hacer -por los jóvenes y con ellos- un ambiente distinto, es una urgencia. Es abrir un camino novedoso, aunque no nuevo en la Iglesia. Es un mirar a las primeras comunidades e imaginarnos intercambios llenos de vida que motivaban procesos de maduración en la fe, que potenciaban la identidad personal y comunitaria, la capacidad profética y misionera. Esta opción acentúa una pastoral integral antropológica y kerygmática al mismo tiempo. También desde México lo remarca Garriga González:
Una propuesta pastoral basada en esta mirada integradora es, a la vez, anuncio explícito de la salvación realizada en Jesús y proceso de fe que, con sus luces y sombras, parte desde la realidad humana y las experiencias actuales de los jóvenes. No se rechaza lo antropológico en función de lo kerygmático ni viceversa. Se propone un estilo de conocer y seguir a Jesús que integre el anuncio y la experiencia específica de su señorío en nuestra historia, pero sin que esto implique un alejamiento de las realidades concretas verificadas en el hoy de esta historia. (2009: 79)

\section{II- Hacer ambiente en la pastoral juvenil}

Nos referimos aquí al ambiente como todo espacio/momento/circunstancia en donde se desarrollan procesos de formación, de enseñanza y de aprendizaje, pero más que nada de interacciones interpersonales. Si nos ubicamos en un salón de clases o de catequesis, podemos pensar en la ambientación, que tiene que ver con el 
mobiliario y la decoración. El ambiente educativo también se hace con la propuesta educativa, de contenidos en sí (planificada, organizada) o con la selección y distribución de recursos concretos (ubicación de sillas o almohadones, o ambientar con luz, música o velas en un momento de celebración). Pero aquí, sin excluir lo anterior, estamos pensando en la "atmósfera" o el "clima" que se genera a partir del trato, los gestos, la acogida. Y por tanto, este ambiente lo experienciamos, lo sentimos, le percibimos. Podemos relacionar este clima con la descripción que hace Jean Vanier sobre la comunión:

En la comunión uno se vuelve vulnerable, se deja tocar por el otro. Se da la reciprocidad: una reciprocidad que pasa por la mirada, por el tacto. Es un tomar y dar amor, un reconocimiento mutuo que puede hacer brotar la celebración y la sonrisa o puede llegar a lo profundo con la compasión y las lágrimas. La comunión se fundamenta en una confianza mutua en la que cada uno da al otro y recibe en lo más profundo y silencioso de su ser. La comunión es distinta a la educación o a la pedagogía. En la educación, si no está fundamentada en la comunión, se ayuda y se educa al otro; pero el que educa se queda como superior. El sabe, el otro no (2011: 51).

Muchos lugares se transforman en espacios posibles de pastoral juvenil: un salón parroquial, el templo, un aula de colegio, un parque... Los espacios físicos pueden ser mejores o peores, pero el ambiente se hace educativo y formativo en la fe, cuando hay encuentro, comunión y compartir experiencial; ${ }^{2}$ cuando existe la posibilidad de un desenvolvimiento humano en confianza, bienestar y seguridad. Puede entonces existir la infraestructura más adecuada, la mejor organiza-

2 El método de formación experiencial es uno de los sugeridos por la propuesta latinoamericana de pastoral juvenil. Consultar Sección de Juventud CELAM en SEJ-CELAM (1995) Civilización del Amor. Tarea y Esperanza. Comisión Episcopal Mexicana de pastoral juvenil, № 303 ción y planificación del evento pastoral, pero el "ambiente" puede dejar trunca la evangelización y la experiencia interior de fe. De manera contraria, un diálogo improvisado en un corredor puede ser motor de decisiones de conversión cuando Jesús se hace presente en el encuentro entre dos personas.

El ambiente evangelizador promueve comunicación de vida y permite interacciones positivas: tareas compartidas y colaborativas, escucha mutua, expresión y respeto en la demostración de opiniones y sentimientos propios y ajenos; o sea un contexto de afecto, respeto, claridad.

Benedicto XVI ha hablado de "emergencia educativa" porque nos explica que es cada vez más arduo transmitir a las nuevas generaciones los valores de fondo y un comportamiento ético, humano. Los pastoralistas son parte de esta "emergencia" porque Jesús y su Iglesia necesita disponer de hombres y mujeres que con la propia conducta de vida sostengan el compromiso evangelizador que viven, que sean testigos creíbles (Lineamenta 22, Sínodo 2012). Se precisan agentes de pastoral que busquen la santidad; y eso requiere de la gracia de Dios y exige formación, esfuerzo, perseverancia y oración; sin olvidarse del fundamento de la nueva evangelización: el Espíritu Santo. Nuestra Iglesia necesita "muchos y cualificados evangelizadores que, con nuevo ardor, renovado entusiasmo, fino espíritu eclesial, desbordantes de fe y esperanza, hablen cada vez más de Jesucristo" (Juan Pablo II, 2003).

Sea cual sea el ámbito y la metodología de la Pastoral Juvenil, esta debe llevar a una relación del evangelizado con el evangelizador, cimentada en el amor, a ejemplo de Jesucristo, el Maestro. Una metodología experimental, transformadora y liberadora, participativa, personalizante y personalizada, integral, coherente, testimonial y comunitaria (Civilización del Amor. Tarea y Esperanza, 2000) con momentos de enseñanzas, actividades, 
interioridad y celebración, no puede construirse fuera de un ambiente de vida.

Toda relación educativa y formativa supone una auténtica y concreta relación vital. Cuanto más vital sea esa relación y esos intercambios, habrá posibilidad de mayores y más profundos aprendizajes. El ambiente de la Pastoral Juvenil debiera ser un lugar de vida, en el que los jóvenes aprendan a conocerse y conocer a otros re-conociendo la presencia de Jesús en cada uno. Debiera ser un lugar de salvación, un lugar en donde se escuche hablar de Dios y se busque vivir el Evangelio, se aprenda a vincularse con Jesús como con un amigo en quien podemos confiar.

La Pastoral es la posibilidad de protección y de prevención, porque se reconoce el valor que para esta etapa de la vida tienen los amigos, los valores que se van asimilando, la imagen de los jóvenes mayores. Es un lugar donde se es aceptado y se propone aceptar a los otros como son, un lugar en donde se integre a todos/as. Un lugar para aprender a comunicarse, donde se pueda hablar de lo que les pasa y se puedan sentir acompañados en sus dificultades juveniles. Un trato diferente que vaya gestando un ambiente distinto, es lo esperable en la Pastoral Juvenil. Las viejas palabras de Juan Pablo II siguen estando vigentes:

Los jóvenes son una gran fuerza social y evangelizadora. En el encuentro de ellos con Cristo vivo, se fundan la esperanza y las expectativas de un futuro de mayor comunión y solidaridad para la Iglesia y la sociedad. El proceso de formación de los jóvenes debe ser constante y dinámico, adecuado para ayudarlos a encontrar su lugar en la Iglesia y en el mundo. La Iglesia se compromete a mantener su opción pastoral y misionera por los jóvenes para que puedan hoy encontrar a Cristo vivo. Deben ser los jóvenes cristianos, formados con una conciencia misionera madura, los apóstoles de sus coetáneos. Es necesaria una acción misionera que llegue a los jóvenes en sus propios ambientes, como el colegio, la universidad, el mundo del trabajo... (Juan Pablo II, 1999: 47).

\section{III-Trato, comunicación y vinculación}

Un día Jesús le dijo a sus discípulos: "Ustedes son la luz del mundo y la sal de la tierra" (Mt 5, 13-14). ¿Puede decir eso hoy Jesús de nosotros como pastoralistas, asesores, coordinadores, animadores de la Pastoral Juvenil?

Ser luz, ser sal, ser testimonio (ya había expresado Juan Pablo II que este mundo necesita más testigos que maestros) implica estar en el mundo sin ser del mundo (Juan 17, 16). Y este camino es un camino de comunión, de unidad, de fraternidad y alianza con los demás. El pastoralista trabaja para la comunidad, en comunidad y desde una comunidad eclesial. Y la comunidad implica relación, encuentro con toda la carga y el valor antropológico que nos hace seres humanos. Podemos pensar en encuentros más breves como el de Jesús con Zaqueo, con Nicodemo, con la Samaritana que llevaron a reflexiones profundas y cambios que marcaron las vidas de esas personas. De igual manera hubo encuentros y llamadas que cambiaron la vida de hombres y mujeres que se decidieron a seguir al Maestro: los apóstoles, los discípulos.

El mandato de Jesús incluye una vida de comunión: "ámense mutuamente unos a otros, como yo los he amado porque en eso los demás reconocerán que son discípulos míos" (Juan 13, 34-35). "El amor que es comunicación y vinculación, se hace presente en el trato entre las personas. Podríamos decir que el termómetro de la madurez humana y de la santidad, está en el trato" (Martensen, 2006: 6).

Al ser creados a imagen y semejanza de Dios Padre, fuimos creados con capacidad de ser dueños de sí para entregarnos y donarnos. Es el camino de "éxodo" de salir de nosotros y de llegar a nuestro prójimo por medio de la autodonación. 
Y la vida del agente de pastoral -así como la de cualquier discípulo de Cristo- significa transitar este proceso para darse y que los jóvenes se queden con Jesús y no con nuestra "sabiduría humana", ni con simplemente nuestra "buena gente".

La vinculación con los semejantes se visualiza y percibe en el trato. Una espiritualidad integral implica buscar hacer vida el mandato de Dios: permanecer en su amor, porque Él es amor y así, Dios permanecerá en nosotros (Juan 4, 16b) y esta permanencia es sobretodo, revestirnos del amor que es el vínculo de la perfección (Col. 3, 12-14).

Podemos revisar nuestros ambientes de pastoral, las parroquias, nuestras reuniones y repasar nuestro trato iEs nuestro trato evangelizador? ¿Cuántas veces aparece la impaciencia, la rivalidad, las malas contestaciones, el autoritarismo, la división entre los grupos, la falta de un saludo acogedor, de una escucha atenta? ¿Es nuestro trato amable, cordial, servicial, bondadoso con el que llega, se acerca, pregunta? ¿Vivimos parados en la caridad del trato o reaccionamos desde nuestra impulsividad, individualidad y agresividad? Estas son preguntas para autoevaluar nuestro trato porque toda comunidad cristiana está llamada a ser imagen de la primera comunidad (Hechos 2, 42-47) y ser signo de la presencia de Dios en el amor.

No basta con saber que Jesús está en el prójimo. Debemos aprender a tratar a Jesús en el prójimo porque el lenguaje vivo de la evangelización es, el primer lugar el testimonio de la vida en el amor. "Evangelizar no es, ante todo, hablar de Dios o pensar y reflexionar sobre él, ni tampoco expresar una vivencia crédula y sentimental de religiosidad; es vivir construyendo el Reino del amor de Dios en la vinculación y el quehacer de la vida personal, familiar, eclesial y social" (Martensen, 2006: 54).

El agente de pastoral está llamado a ser un pedagogo de la comunicación. Quiere y busca que el mensaje se haga vida. En Jesús tenemos siempre el modelo, el camino, la vida. Como el Maestro Bueno, cada agente de pastoral deberá

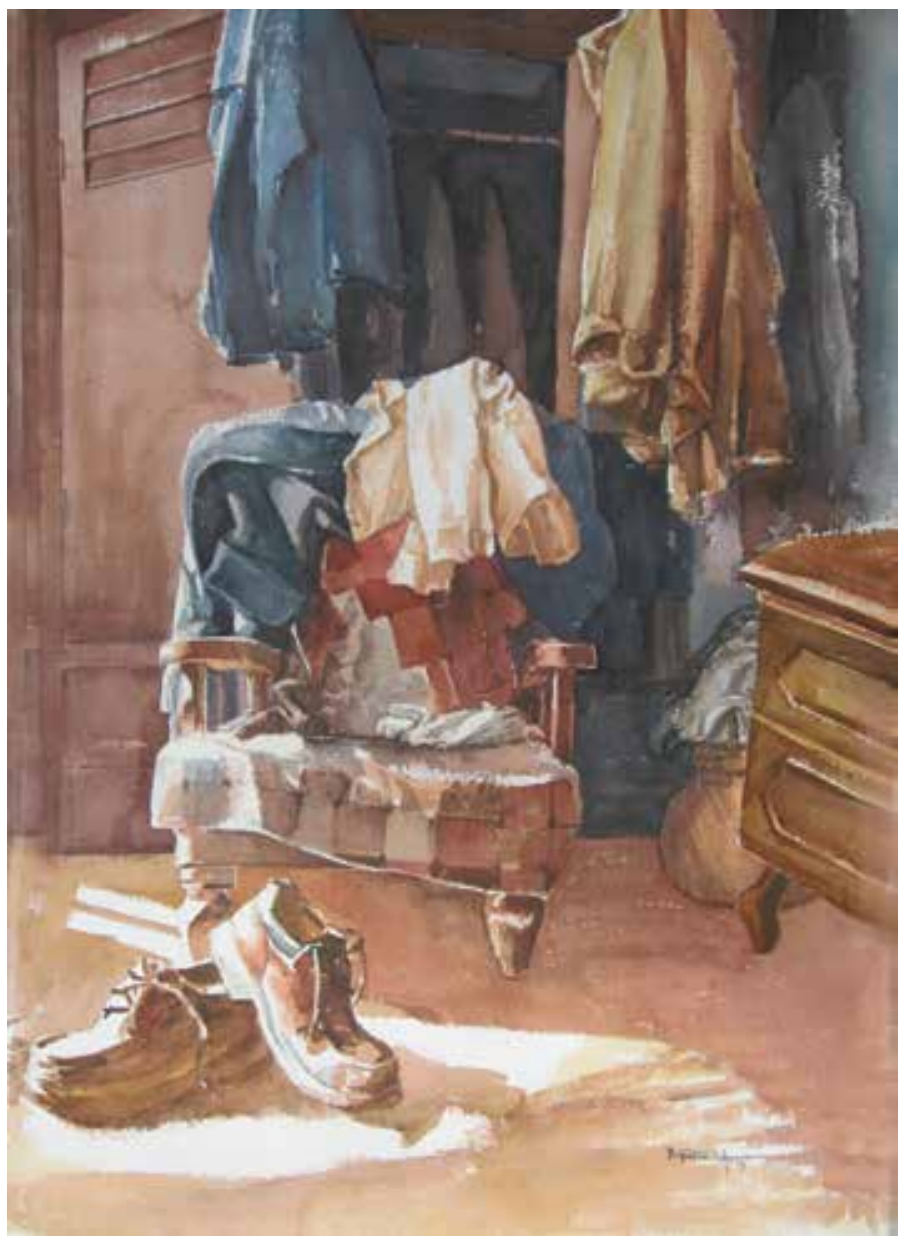

El rincón de las ausencias, acuarela, 70×50

hacer presente la "mirada amorosa" que es inicio y condición de todo encuentro verdaderamente humano, de todo trato fraterno. Los evangelios nos relatan la profunda huella que dejó, en los primeros discípulos, la mirada de Jesús. Por eso, debemos "mirar" con los ojos de Dios y "tratar" con la caridad de su corazón.

\section{IV-Fraternidad y encuentro}

El amor es expansivo y misional, no se queda encerrado, se dona y gesta comunidad. El "miren como se aman" (Hechos 4, 32-37) es expresión comunitaria. La fe crece en grupo y se alimenta compartiéndola. Dios quiso salvarnos 


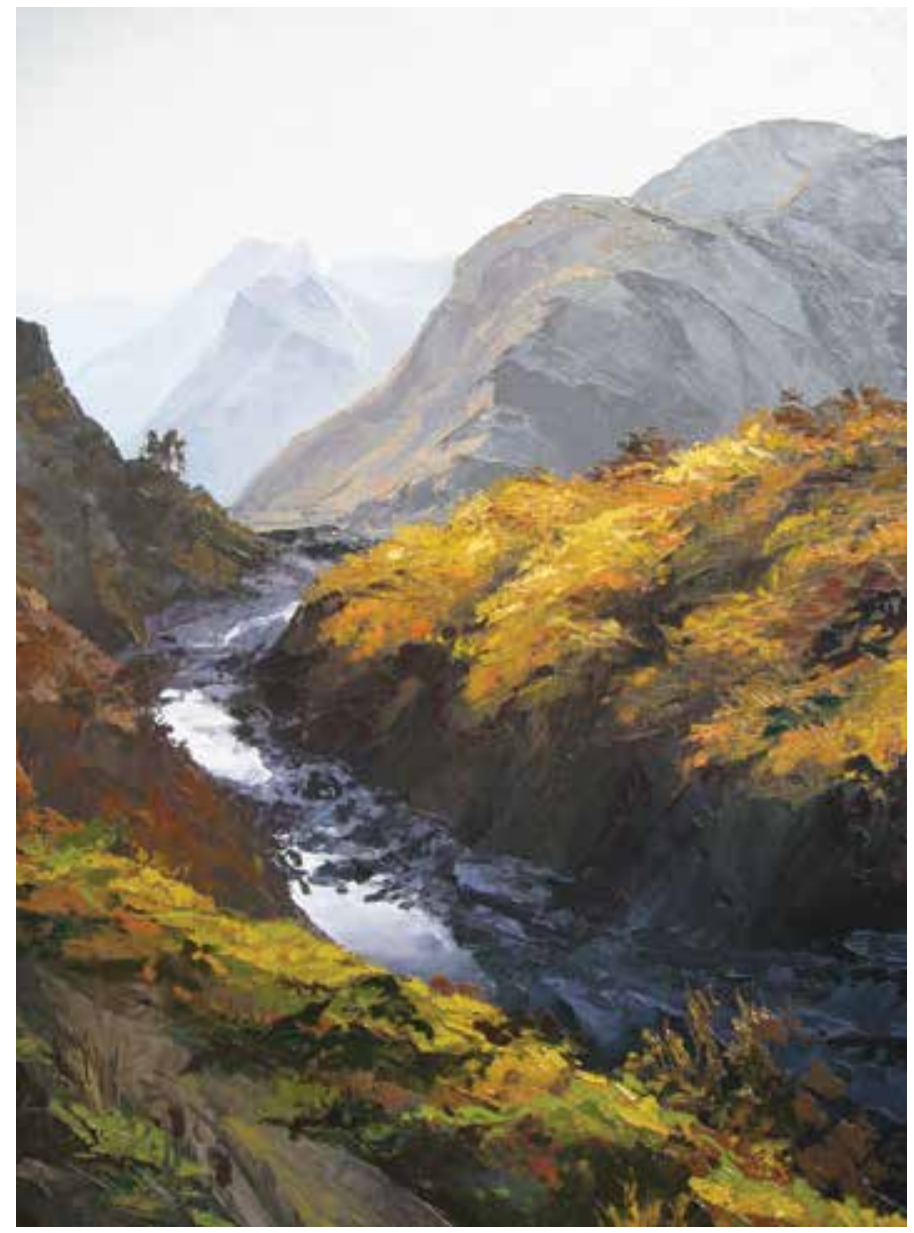

El río seco, óleo sobre lienzo, 80×60

no aisladamente, sino formando un pueblo. No es posible vivir la fe sin la comunidad: en ella se recibe, en ella se celebra, desde ella se es enviado a la misión. La relación pastoral pasa, pues, por la comunidad eclesial.

Somos hermanos porque somos hijos del mismo Padre. Somos templo del Espíritu Santo que habita en nosotros. Por eso cuando nos relacionamos lo hacemos con el otro, con el prójimo y con la presencia de la Trinidad que habita en nuestros hermanos. El amor ha sido derramado en nuestros corazones (Rom. 5, 5) y desde ese amor tenemos que aprender a ser y hacer comu- nidad. Con el amor que Dios nos tiene y nos comunica, amamos a los demás. Es importante trabajar en los ámbitos, ambientes e itinerarios de la Pastoral Juvenil este aspecto que es la fraternidad, el compartir en común, el abrirse y escuchar, el recibir y acoger. Jesús nos pensó en su Iglesia como familia de Dios; nuestro trato se esperaría que sea siempre de familiaridad y caridad.

Alfonso López Quintas, catedrático de Filosofía en la Universidad Complutense de Madrid, enseña que todo ámbito de encuentro, es un ámbito de formación y este concepto lo aplica a los espacios educativos. Cuando no hay ámbito de formación -dice Quintás- podrá haber cualquier otra cosa por ejemplo información, pero no formación. Cuando se vive un verdadero encuentro, siempre habrá una verdadera construcción y debe existir la acogida. Podemos relacionarnos, pero no encontrarnos y generar así intercambios instrumentales o mercantiles, contactos superficiales, choques virtuales, pero de ningún modo un encuentro.

El encuentro con el otro requiere responsabilidad, un trato ético, justo, amoroso. Y la palabra es un instrumento de este encuentro, de comunicación de sí mismo y medio de personalización. En la era de la información y de las comunicaciones, constantemente nos quejamos y nos topamos con incomunicaciones. Comunicamos cosas, ideas, informamos y nos informamos, pero la mayoría de las veces no nos comunicamos de ser a ser. El aprendizaje del encuentro requiere de libertad y la libertad, es lo que construye sujetos autónomos y éticos.

El encuentro no es mera proximidad, sino que supone un ir y venir entre los seres que interactúan: una interpelación. Cuando uno habla y no hay respuesta, o cuando uno habla para acallar al otro, no hay encuentro. Sí lo hay, en cambio, cuando se crea una atmósfera en la que fluyen las preguntas y las respuestas, la comunicación y el silencio, la mirada y el respeto...

El personalismo dialogal proclama la trascendencia del "tú" para la existencia humana, o sea superar el individualismo y descubrir al "otro" 
para abrirse a los demás. Existir es co-existir, "ser para el encuentro" y la comunión. Para Buber, yo soy mi relación. No un yo que entra en relación, sino un yo que sale de la relación, emerge de ella. La relación me define; soy de acuerdo a cómo me manejo (Barylko, 1998).

La pedagogía del encuentro se rige por la dimensión pragmática del lenguaje y se descubre que todo lenguaje es diálogo. La conversación es una actividad de uno-con-otro; es entendersecon-alguien-sobre-algo; es un decir y dejarsedecir; es una actividad reversible de apelaciones y respuestas, que transforma a los interlocutores: en un encuentro conversacional, uno deja la esfera del yo para ingresar en la del nosotros e instaurar un intercambio entre el yo y el tú (Gadamer, 1992: 150) que discurre como un fluir de coordinaciones consensuales de acción, tal como sucede en el juego. En el encuentro creamos un campo de juego común, un campo de libertad común, un campo para comunicarnos de yo a tú.

Una pedagogía del encuentro tiene en cuenta a sujetos íntegros, con ricas experiencias capaces de instaurar un diálogo continuo con uno mismo, con los otros y con el mundo. EI sujeto se construye así en el intercambio, en la capacidad de entenderse y comunicarse con los otros para comprender el mundo y la convivencia con otros sujetos, para expresar las propias emociones-razones y someterlas a la crítica de los demás.

Los educadores-pastoralistas somos seres de comunicación; los sistemas educativos y los espacios de pastoral son sistemas de comunicación; los jóvenes son seres que crecen en la diferencia y en la comunicación. Una comunicación debe ser estimuladora para el otro, o sea que lo invite a salir de sí, a entregarse, a enriquecerse, a crecer. El ambiente de pastoral será entonces rico cuando invite al diálogo, a la comunicación y la escucha con Dios, con los otros, con uno mismo.

Volviendo a Quintás, el autor incorpora el concepto de "experiencias reversibles", que son experiencias que tienen doble dirección y que son importantísimas en la vida humana. En toda interacción bien entendida existen estas experien- cias reversibles, y este tipo de intercambios; por ejemplo el educador influye en el educando y el educando en el educador, el agente de pastoral en el joven y viceversa. Lo contrario de este tipo de experiencia es una experiencia lineal: del sujeto al objeto. Quintás ofrece un ejemplo:

Yo le doy un impulso al bolígrafo y el bolígrafo padece ese impulso y ahí se queda. El esquema que vertebra esta acción es el esquema acción/ pasión: yo actúo-él padece. En la experiencia reversible no es así; yo actúo sobre usted, usted actúa sobre mí, son dos actuaciones libres que nos complementan a los dos. Esto nos enriquece muchísimo (1999).

Un rasgo de madurez en las personas es la posibilidad de actuar mediante experiencias reversibles y cada vez menos lineales. Por ejemplo, un agente de pastoral, que espera solo que los jóvenes con los que trabaja reciban lo que él les da, escuchen lo que él habla, sería un pastoralista que vive de experiencias lineales. Pero si el pastoralista habla, actúa sobre los jóvenes, pero ellos también reaccionan, por ejemplo, con autonomía y criticidad, relacionándose entre sí, haciendo propuestas, planteando preguntas e iniciativas, compartiendo ejemplos y experiencias surge es una práctica reversible en el encuentro de pastoral. Entonces, para que haya construcción de sujetos debe haber formación y para que haya formación debe ocurrir un encuentro entre sujetos, lo que aumenta la calidad de vida, la calidad de la formación y una autentica conversión.

Es necesario pensar en una pastoral juvenil desde la pedagogía del sujeto. Esto es trascender una formación transmisora que desarrolle individuos dependientes y alienados y optar por una formación para la creación de sujetos con autonomía social y ética-moral, con posibilidad de tomar decisiones, proponer nuevos caminos, hacer y hacerse nuevas preguntas, repensar la realidad, autocriticarse, construir una nueva civilización desde sus trabajos y profesiones, desde la opción vocacional (familiar o consagrada). Optar por 
una formación para el encuentro y la fraternidad, para el desarrollo del diálogo. Una educación respetuosa de las culturas y de las diferencias, con reconocimiento de las características del joven, con orientación hacia la vida y sus necesidades, sustentada por los valores humanos y por los valores del Evangelio de Jesús.

El encuentro con el otro contiene una vinculación fraterna: la amistad, el compañerismo, lo familiar, lo social, lo religioso comunitario. A nivel pastoral un desafío importante es la falta de vida fraterna en los grupos parroquiales, en los ambientes litúrgicos, en los ambientes pastorales, en las escuelas y colegios y hasta en muchas comunidades religiosas. Como Iglesia y Cuerpo de Jesús somos miembros los unos de los otros (Ef. 4, 25), porque el amor comunitario es un amor trinitario. Cuando hay rivalidad y competencia, cuando hay autoritarismo y deseos de sobresalir, se apaga el espíritu servicial y el anhelo de santidad. No se trata de "dirigir", "conducir", "mandar" o "cumplir una función", sino de "dar alma", "dar ánimo", de "dar vida" a los jóvenes y a la pastoral juvenil. Es un servicio evangelizador que exige, acción, reflexión, amor porque -parafraseando a Don Bosco- la pastoral es una "cuestión del corazón".

¡Qué importante es enseñar en la pastoral que debemos caminar en encuentro y en fraternidad! No sólo saber que somos hijos del mismo Padre del Cielo, sino que podemos hacer realidad en la tierra la vida fraterna cuando compartimos, trabajamos con otros, somos bondadosos, desarrollamos las virtudes y nos amamos mutuamente en gestos y vida concreta. Hay que orar pidiendo esta gracia y poner en un lugar esencial la enseñanza que el Señor nos deja en la Última Cena: "Les doy un mandamiento nuevo: ámense los unos a los otros. Así como yo los he amado, ámense también ustedes los unos a los otros. En esto todos reconocerán que ustedes son mis discípulos: en el amor que se tengan los unos a los otros" (Juan 14, 34-35).
Garriga González remarca la importancia del ambiente experiencial y la relaciona con el trabajo en pastoral juvenil, cuando dice:

En la fe cristiana, la praxis concreta de las comunidades primitivas, en su vida cotidiana, es anterior a cualquier teoría o dogma de fe. Este privilegio de la experiencia de la vida, como fuente de la fe que luego se expresa en palabras, es una oportunidad de conexión con el mundo juvenil, buscando una toma de conciencia de su actuar cotidiano, de sus valores ya presentes, de su fe que nace desde la vida (2009: 75-76).

El trabajo en pequeños grupos facilita la creación de lazos profundos de fraternidad, permite compartir, ayuda a enfrentar los desafíos de la vida, educa a mirar y descubrir junto con otros la realidad, permite encontrarse con Jesús de Nazaret y adherir a Él y a su proyecto de vida, impulsa la renovación permanente del compromiso de servicio y da solidez a la proyección misionera expresada en el testimonio personal, en el descubrimiento de opciones vocacionales y en el compromiso civilizatorio y la transformación de la realidad.

Las pequeñas comunidades y grupos son una experiencia central de la evangelización, del trabajo fraterno y del anuncio kerigmático. Se trata de grupos pequeños, estables y mixtos, que se constituyen en un lugar de crecimiento, formación, referencia y realización personal y comunitaria del joven. Las palabras de Monseñor Castro en COMLA VI (1999) son de fuerza al respecto:

Por eso nosotros estamos llamados primero a vivir el Evangelio. La vivencia de la pascua es como la de una explosión, el kerigma vivido no es fruto de un mandato, de una explicación racional, de una lección de catecismo. Es una explosión, que agarra todo el ser y despierta estupor y perplejidad. Que implica un encuentro vivo, emocionante, de ojos abiertos y de corazón palpitante con el Señor. Que se vive no sólo sino en forma comunitaria. Que 


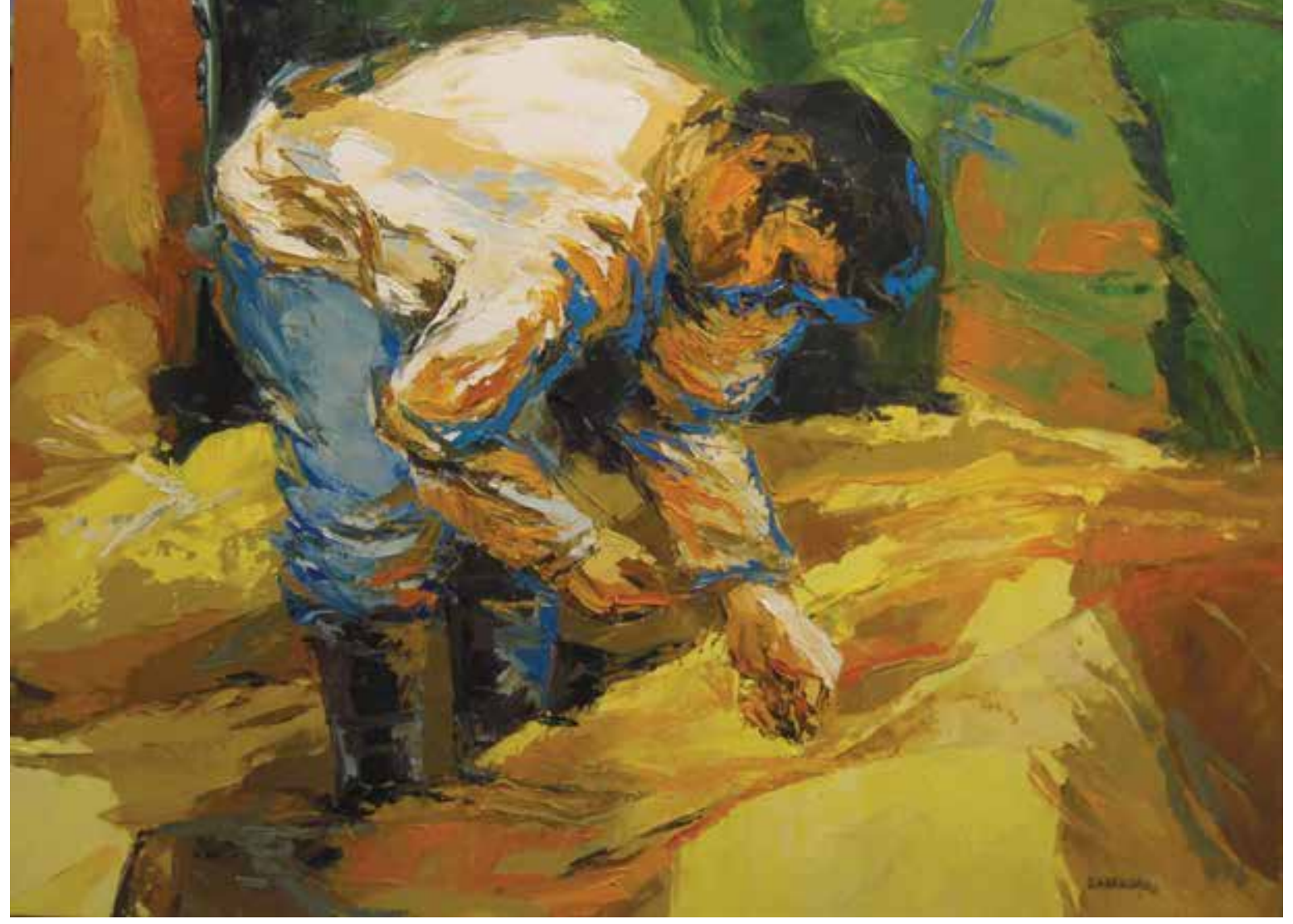

El sembrador, óleo sobre lienzo, 60x80

pide acogida de amor y de discernimiento de la Palabra para no confundirlo con las propias fantasías. Que inicia un proceso vivo, existencial. Luego esta vivencia no deja igual a la persona, la cambia y la lanza a la misión. La misión es un movimiento que no para jamás, que lleva más allá de las fronteras, a todos los rincones. El kerigma es anuncio testimonial, que está en la base, por eso es primer anuncio. Es el anuncio fundamental, aquello sin lo cual lo demás quedaría en el aire. Busca generar la vida de fe. Es la invitación a recibir a Jesús como Salvador y Señor, pero es un anuncio trinitario, porque se habla de Cristo como enviado del Padre con la fuerza del Espíritu. Este anuncio es una invitación emotiva y cordial porque se dirige al corazón, a ese centro donde se toman las decisiones existenciales y definitivas. Hay que tener puntería, hay que disparar al corazón. No es una invitación a aprenderse algo con la cabeza sino a decidirse por Alguien. Es un anuncio que suscita una profunda emoción (Hch. 2, 37). Un anuncio vivido comunitariamente, que funda la Iglesia.

\section{V- El testimonio empieza por casa...}

El pastoralista es un hermano/a que ha recibido un llamado y un don de Dios para este servicio y que, a imagen de Jesús Buen Pastor, acompaña el camino y los pasos de muchos jóvenes. Facilita el compartir, la participación y espontaneidad de los jóvenes. Esta intervención promueve así el diálogo y la presencia viva y eficaz de la Palabra; es decir, busca hacer posible el diálogo entre Dios y los hombres, sus hijos. La espiritualidad del agente de pastoral basada en la Palabra de Dios y el testimonio de la fe en actitudes y opciones de vida del servidor, son parte de los fundamentos del servicio y ministerio que desarrolla, porque es testigo que transmite lo que ha visto y oído (Juan 1, 1-4) con su mensaje pero principalmente con su vida, da testimonio de Dios y de lo que Dios ha hecho en él.

Tener un corazón de pastor debiera ser el anhelo de todo agente de pastoral, para conducir al rebaño de jóvenes que el Señor nos confía. "Yo soy el Buen Pastor, conozco a mis ovejas y mis 
oraciones o vamos a amar al Señor y a encontrarnos con Dios? ¿Cómo podemos describir nuestra "familiaridad" con Dios?

Un pastoralista "acelerado" que vive haciendo pero que no cultiva estos momentos de encuentro con Dios, da y no recibe de lo alto, se va quedando vacío de espiritualidad. La fe nos lleva a vivir desde Dios, en Dios y para Dios porque en Él nos realizamos (Gal. 2, 19; Rom. 6,10). Necesitamos que la fe nos abra a la mirada de Dios sobre nuestra vida. ¿Cómo ve Dios nuestra vida interior? ¿Y cómo la reciben los demás? No podemos dar y transmitir lo que nosotros no tenemos.

Detrás de cada animador juvenil, de cada persona que desde la Iglesia trabaja por un joven hay un llamado, una elección, una vocación. Esta es una verdad fundante de nuestra identidad: hemos sido llamados por Dios, elegidos por Él. Creemos y confesamos la iniciativa de amor que hay en el origen de lo que somos. Nos reconocemos como don, como gracia. Y hemos sido llamados para estar con Él. Por eso nos decimos cristianos, nos reconocemos en estrecha relación con Cristo. Con el apóstol Pablo podemos decir: "... y ya no vivo yo, sino que Cristo vive en mí..." (Gal. 2, 20). Ese vivir con Cristo es realmente una vida nueva: la vida del cristiano, y determina todo lo que se es y se hace. De ahí que todo agente de pastoral debe procurar permanecer en el Señor (Juan 15,4 ) y cuidar, con la oración, su corazón transformado con la gracia, porque es lo que tiene para ofrecer y en donde está su verdadero "tesoro" (Lc 12, 34).

\section{Epílogo}

Los obispos en Aparecida reafirmaron la opción preferencial -efectiva y afectiva- por los jóvenes, en comunión con las anteriores Conferencias del Episcopado y desde allí invitaron a renovar el dinamismo de las pequeñas comunidades como lugar privilegiado para la evangelización de los discípulos y misioneros. Esto representa para la Pastoral Juvenil Latinoamericana una invitación para recrear su propuesta, asumiendo los desafíos de la realidad actual de miles de jóvenes que buscan en ella un espacio de acogida fraterna, participación y proyección. Si se sienten amados, como realmente Jesús los ama, encontrarán un espacio para crecer humana y discipularmente, aún en medio de tendencias individualistas y masificantes.

Pretendimos aquí reafirmar que la opción de tomar a Jesús como modelo relacional, de encuentro comunitario, de trato humano y fraterno es una elección que construye un ambiente evangelizador que -fundamentado en dimensiones antropológicas comunitarias y kerygmáticasse convierte en eje clave de la Pastoral Juvenil.

\section{Bibliografía}

Barylko J.

1998. La filosofía, una invitación a pensar. Argentina: Ediciones Planeta.

Benedicto XVI.

2009. "Discurso durante la inauguración de la Asamblea eclesial de la diócesis de Roma”. Disponible en: http://www.vatican. va/holy_father/benedict_xvi/speeches/2009/ may/documents/hf_ben-xvi_spe_20090526_ convegno-diocesi-rm_sp.html

2012. "Reavivar en la Iglesia aquella positividad del anuncio de Cristo al hombre contemporáneo". Disponible en http://www.zenit. org/rssspanish-43338

Bergoglio J. M.

2005 Encuentro Arquidiocesano de Catequesis (EAC). Buenos Aires. 2007. Discurso en la V Conferencia General del Episcopado Latinoamericano en Aparecida Disponible en http://www.aicaold.com.ar/index2. php?pag=VC_VConferencia\#Participación_ argentina

Castilleja De León P.

2010. "El Modelo de la Pastoral Juvenil Latinoamericana”. En Medellín: teología y pastoral para América Latina. Vol. 36. № 144. 463-486. 
Castillo Mattasoglio C.

2010 "La opción por los jóvenes en Aparecida" En Medellín: teología y pastoral para América Latina, Vol. 36, №. 144, 20.487-517.

CELAM.

1979. Puebla: II Conferencia General del Episcopado Latinoamericano.

1995. Civilización del Amor. Tarea y Esperanza, orientaciones para una Pastoral Juvenil Latinoamericana. Bogotá.

2003 Proyecto de Vida: Camino vocacional de la pastoral juvenil. Documentos CELAM No 162. Bogotá.

2007. Aparecida. Discípulos y Misioneros de Jesucristo para que nuestros pueblos en El tengan vida. Bogotá: San Pablo.

1999. Eclessia in América.

2003. "La evangelización y los pobres necesitan testigos de Cristo". Ciudad del Vaticano, 27 marzo 2003. Disponible Zenit.org http:// catinfor.com/catholicnet2000/?p=11150

Castro Q. L. A.

1999. "El paganismo como pregunta, el kerygma como respuesta". En: Colombia, COMLA VI. Disponible en http://misiones.catholic. net/comla6_conf1.htm

Gadamer, $\mathrm{H}$.

1992 "Verdad y Método". Tomo II. Ediciones Sígueme. Salamanca. 150-151.

Garriga González, M. A.

2009. "El principio misericordia y la pastoral juvenil en la posmodernidad" En Revista Iberoamericana de Teología. Vol. V. Núm 8. México: Universidad Iberoamericana. 59-85. Disponible en http://www.redalyc.org/articulo.oa?id=125212539003

Gil M.

2010. "La interioridad del catequista" en Revista Cristo Vive, Aleluia. No. 171. Ed. Movimiento de la Palabra de Dios. Argentina. 23-25.

2010. "Experiencia de vida y testimonio". En: Revista Cristo Vive, Aleluia. No. 173. Ed.
Movimiento de la Palabra de Dios. Argentina. 10-11.

Lineamenta de la XIII Asamblea General Ordinaria del Sínodo de los Obispos.

2012. "La Iglesia existe para evangelizar". Disponible en www.vatican.va/.../rc_synod_ doc_20110202_lineamenta-xiii-assemb...

López Quintas, A.

1996. “¿Cómo lograr una formación integral?". Madrid: San Pablo.

1999"LaFormaciónAdecuadaalaConfiguración de un Nuevo Humanismo". Conferencia, Universidad de São Paulo, Disponible en http://www.hottopos.com.br/mirand9/quintas. htm

http://es.catholic.net/educadorescatolicos/693/2399/articulo.php?id=21849

http://www.cnice.mecd.es/tematicas/etica/ index.html

Martensen R.

2006. Grupos comunitarios de oración y servicio. Argentina: Editorial de la Palabra de Dios.

Paulo VI.

1975. "El anuncio del Evangelio hoy". Bogotá: Ediciones Paulina.

Peresson M.

2006. "Educar en Positivo". En: Sophia, Colección de Filosofía de la Educación. No. 1. Quito. Ecuador: Universidad Politécnica Salesiana - AbyaYala.

SEJ-CELAM

1995. Civilización del Amor. Tarea y Esperanza. Comisión Episcopal Mexicana de pastoral juvenil, Morelia, Michoacán.

2006. "Manual de la pastoral juvenil", Bogotá, Colombia Disponible en http://www.pastoralhubenil.com/downloads/Manualdelapastoral juvenil.pdf.

Vanier J.

2011. Cada persona es una historia sagrada. Buenos Aires: Ágape. 